\title{
ENHANCED ACCESSIBILITY: AN ELEVATOR WITH AN INTERACTIVE MEDIA SURFACE
}

\author{
Jacobson, Susanne; \\ Ranne, Jaakko \\ KONE Corporation
}

\begin{abstract}
This exploratory research paper discusses the importance of experiential qualities in products that have accessible and assistive uses. The focus is on products that may have an ambiguous user experience. Concepts of multisensory user experience and accessibility are presented as an introduction to the topic.

The paper builds on the findings of a preliminary user study that was conducted in a joint multinational and cross-industrial project that was externally funded. In the study, users' experiences of an accessible means of transport, an elevator prototype with an interactive media surface, were explored. The study comprised a thinking aloud task and a design game.

The demonstrated colours, lights and their movements created various kinds of associations among the participating users. The participants also ideated about the product's alternative applications, some of which concerned accessibility, while others extended beyond it.

The findings show that adding experiential product qualities enhances the user experience in terms of various associations and applications that extend beyond accessibility and the original use.
\end{abstract}

Keywords: Case study, Inclusive design, Multisensory product experience, User centred design

\section{Contact:}

Jacobson, Susanne Marika

KONE Corporation

Technology and Innovation, Technology Management, Research

Finland

susanne.jacobson@kone.com

Cite this article: Jacobson, S., Ranne, J. (2021) 'Enhanced Accessibility: An Elevator with an Interactive Media Surface', in Proceedings of the International Conference on Engineering Design (ICED21), Gothenburg, Sweden, 16-20 August 2021. DOI:10.1017/pds.2021.138 


\section{INTRODUCTION}

This exploratory research paper discusses the importance of experiential qualities in products that have accessible and assistive applications. The focus is on products that may have an ambiguous user experience, and an elevator is used as an example. The paper presents how adding product qualities that enhance experience can result in a more positive reception among users. The paper builds on the findings of a qualitative user study that was conducted in an industrial context. An accessible means of transport, an elevator prototype, was fitted with an interactive media surface and the user experience and insights were explored. The paper begins with an introduction to multisensory user experience and accessibility, continues with a description of the user study and its context and concludes with an outline and discussion of the findings.

\subsection{Multisensory User Experience}

User experience refers to the act of using a system in a certain time period and, in addition to the used system, it concerns the context of use and its users (Roto et al., 2011, pp. 7-10). The context refers to social, task-related and technical factors. The user is a dynamic actor who receives signals from the environment through their senses and interprets incoming sensory messages based on their previous experiences, personal values, current state of mind, motives and cultural background. This leads to a subjective interpretation of the surroundings and its inherent products. (Desmet and Hekkert, 2007, p. 14, Roto et al., 2011, pp. 7-10.) The system includes qualities related to functionality, aesthetics and a brand image, as well as other qualities, such as the worn look of a product, all of which are interpreted by the user and shape the user experience (ibid., p. 10).

Senses are vital for usability and accessibility, as well as for emotional experiences since they transfer information about emotions and feelings. Although user experience is dependent on personal reflection, various sensory signals create common associations: touch, for example, can relate to a sense of safety and affection or shape product characteristics in the way that a cold object makes a user feel cold (Sonneveld and Schifferstein, 2008, p. 62). Similarly, a product sound can shape the user's perception of product quality (Dal Palù et al., 2018, pp. 25-26; Egmond, 2008, p. 69).

Incoming sensory information is dependent on the signal strength and the amount of simultaneous sensory signals (James et al., 2017, p. 55, 82, ) meaning that when designing systems, products or spaces, the ability to control different sensory signals helps to control the user experience. Coherent multisensory signals strengthen the communication of the intended message (Oviatt, 2017, pp. 34-35), which is particularly relevant when designing systems for users with varying physical [dis]abilities, as well as when striving to elicit specific feelings and emotions. Although the senses transfer individual signals from the environment, the brain combines them into a coherent representation of the surroundings (James et al., 2017, p. 51), which supports the multisensory user experience and the idea that the senses should be evaluated in their entirety instead of focusing on just one sense at a time.

When it comes to elevator experiences, it has been suggested (Rousi, 2013, p. 289) that design should not evoke conscious reactions but rather support the activity that the user was focusing on when they entered the elevator. According to a study on elevator experience, the users primarily had positive sensations about things that did not happen, for example, when an elevator did not get stuck or endanger safety. Moreover, negative reactions correlated with previous negative experiences in elevators and current and previous encounters seemed to blend with and affect the current experience. (Ibid., 2014, p. 20.) The presence of multisensory stimuli does not necessarily mean that the user experience should be active, affective and memorable. However, taking into account the various senses contribute to the process of designing product qualities and functions, some of which are assistive and others, for example, provide aesthetic value. Together they will result in a holistic user experience.

\subsection{Accessibility}

Elevators are inherently accessible and their ultimate purpose is to assist users by providing an accessible means of transport. For some users, particularly people with disabilities, as well as people with, for example, baby strollers and suitcases, elevators are essential. However, accessibility alone does not guarantee a pleasurable user experience.

Accessibility design has several approaches such as Universal Design, Inclusive Design and Design for All. They have historical and geographical differences but roughly share the same aim for products, 
spaces and environments that are accessible to a wide range of users. Universal Design has principles that strive for design that is useful, comfortable, accommodating, tolerant of errors, appropriately sized, as well as easily understandable, communicative and marketable to users with different abilities (The Center for Universal Design, 1997; Coleman et al., 2003, pp. 12-13; Mueller, 2003, p. 319).

Even though usability is a key quality, other qualities such as economic, cultural and environmental, as well as those related to gender and engineering, should also be taken into account in accessibility (The Center for Universal Design). Moreover, experiential and multisensory product qualities should be addressed in order to enhance cognitive and psychological accessibility. These are particularly important in elevators, which are used by people of different ages and abilities in various cultural settings.

However, a universally designed environment does not have to emphasise accessibility. Instead, accessibility could comprise discreet and assistive functions that are only detectable by those people for whom they are essential (Jacobson 2009, 2014). An example of this is audible traffic signals that are based on the sounds of nightingales. For people with visual impairments, they provide a necessary assistive function, whereas for other people they mainly provide aesthetic value. (Jokiniemi, 2007, pp. 58-76.)

Sometimes assistive products and accessible spaces may lack qualities that take into account all the senses and dimensions of the user experience and be regarded as negative, even as stigmatising (e.g. Jacobson 2014). In an elevator context, the sensation of a confined space that ascends and descends rapidly in the company of strangers, might create a sense of claustrophobia and acrophobia and a fear of social situations (Rousi, 2013, p. 290; Rousi, 2014, p. 18). In such situations, product qualities that support positive sensations might draw the user's attention away from negative sensations and enhance the experience.

\section{THE USER STUDY}

\subsection{The Background}

This paper is derived from an exploratory user study that was conducted in a joint multinational and cross-industrial project called InSCOPE ${ }^{1}$. It was funded by the EU Horizon 2020 research and innovation programme from 2017-2020. The aim of the project was to set up an open access pilot line service for hybrid printed electronics. (InSCOPE, 2020.) The participants in the project comprised various research and industrial partners that represented the automotive, healthcare, smart packaging and building sectors. One of the members of the project consortium was KONE Corporation, founded and headquartered in Finland. The company's mission is to "improve the flow of urban life" and its vision is to "create the best People Flow ${ }^{\circledR}$ experience". The company is a global leader in the elevator and escalator industry. (KONE, 2020a.) In the InSCOPE project, KONE aimed to demonstrate more affordable interactive media surfaces in elevators. In this study, media surfaces refer to large, integrated, digital displays. Three subsequent prototypes were developed in collaboration with the project partners. The final prototype was an elevator car with an interactive media surface. The media surface was a printed LED display and was one of the hybrid printed electronics applications developed in the project.

\subsection{The Thinking Aloud Task and the Design Game}

The prototype was tested by four persons who had physical disabilities. One of them also had a visual impairment. They were trained experts by experience in terms of their condition. This group comprised three women and one man between 39-49 years of age. Two of them use a powered wheelchair. One of the participants occasionally used a manual wheelchair, depending on their condition, although they did not use it in the study. One participant had prosthetic legs and also a visual impairment and used a crutch. The participants who used a powered wheelchair could not fully move their hands and another participant had a personal assistant to help them. The participants are presented in Table 1 in terms of their requirements for accessibility but in a way that guarantees their anonymity.

1 International Smart Collaborative Open-access Hybrid Printed Electronics pilot line. 
Table 1. The participants in the user study and their accessibility requirements.

\begin{tabular}{|l|l|l|}
\hline Participant 1 & A physical disability. & $\begin{array}{l}\text { The participant had a manual wheelchair } \\
\text { available although they walked and stood } \\
\text { in the study. }\end{array}$ \\
\hline Participant 3 & A physical disability. & $\begin{array}{l}\text { A powered wheelchair and a personal } \\
\text { assistant. }\end{array}$ \\
\hline Participant 2 & $\begin{array}{l}\text { A physical disability and a } \\
\text { visual impairment. }\end{array}$ & A crutch. \\
\hline Participant 4 & A physical disability. & A powered wheelchair. \\
\hline
\end{tabular}

The participants were recruited by two different networks. The study was conducted at KONE's premises and comprised two parts. The emphasis was on the media surface but the elevator car set the context. Before starting, the participants signed a consent form.

As elevators are an accessible means of conveyance, it was important to engage users who have diverse abilities and requirements. The idea, deriving from accessibility approaches, was that assessing the needs of so-called extreme users would also likely fulfil the needs of other people. This idea is also in line with the aspirations of KONE as the company regards universal design as "a stamp of architectural excellence" and fulfilling the requirements set by users with a disability as a form of usability for all people (KONE, 2020b). Engaging people with disabilities in the study also concretised one of the company's values, namely, care, which includes "embracing diversity and inclusion" (KONE, 2020c).

In the first part of the user study, the participants tested the prototype. The prototype demonstrated different colours, lights and their movements. The changing colours were yellow, orange, red, violet, blue and green. The movements comprised various shapes from points to waves, which emerged and moved in different ways and directions. (Figure 1.)
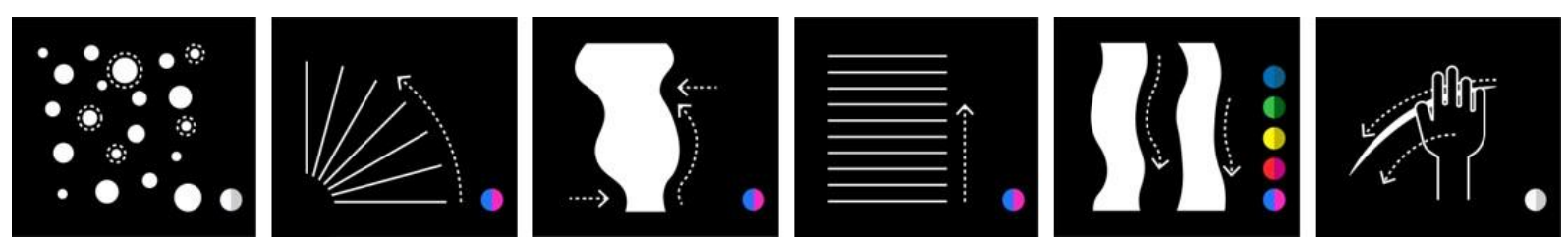

Figure 1. The different combinations of colours, lights and their movements.

The objective was to understand how the participants perceived the different colour, light and movement combinations and how these made them feel. The participants were not informed about the properties of the prototype beforehand because their initial impressions were being sought. However, it was verified beforehand that the participants did not have any condition such as migraine or epilepsy that could be triggered by the bright lights.

The participants were asked to enter the prototype and to think aloud. Two researchers observed and took notes while one researcher operated the prototype. Questions were also asked when the researchers wanted to understand why a participant had said something. After the initial impression, an interactive function was also added that allowed the participants to control the media surface using bodily gestures. The logic of this interactive function was not explained to the participants and some of them eventually needed to be given hints to help them use it. The aim was to understand how the participants perceived the interaction and how it made them feel.

In the second part of the study, the users participated individually in a design game that has been organised by two researchers. The participants were initially asked about the places they visited most frequently and their everyday needs and wishes with regard to these places. The aim was to create a context for identifying challenges and finding solutions for them. The participants then ideated the contents they would like media surfaces to include and where they would like the surfaces to be located. Finally, the participants were asked whether they thought media surfaces should measure and collect data. The purpose of the session was to identify new user-inspired opportunities for media surfaces. Image cards with different themes representing various aspects of life were used as inspiration. These included technology, nature, politics, animals, emotions, relationships, food, activities, mobility, health and materials. The two researchers also asked questions and took notes. (Figure 2.) 


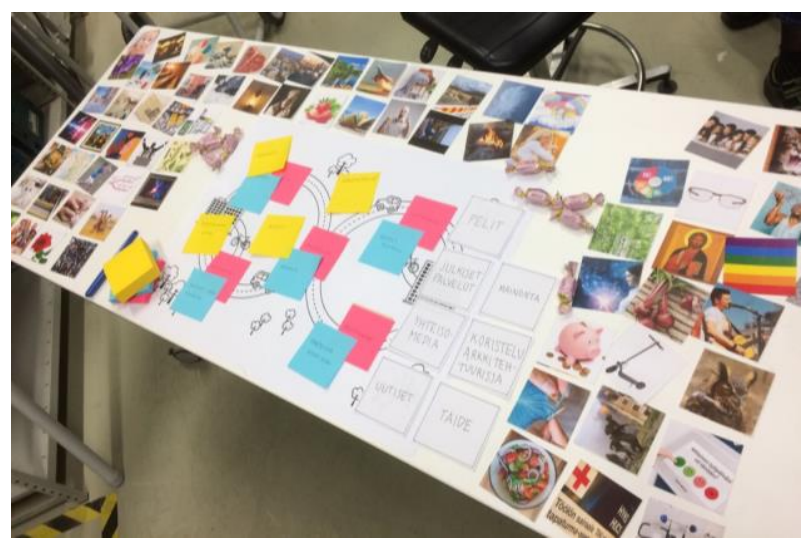

Figure 2. The design game.

The thinking aloud task was audio and video recorded and the design game was audio recorded. For their input, each participant received a gift card. The analysis of the gathered material was data driven. In this research paper, the InSCOPE project's user study and its findings were examined from the perspective of the multisensory user experience, particularly its dimensions that extend beyond accessibility. The user study findings have also been used in another research paper ${ }^{2}$ by the other author of this paper but were approached from a different perspective: the role of experts by experience in corporate social sustainability and responsibility. In addition, a master's thesis ${ }^{3}$ was written during the project.

\section{RESULTS}

The prototype engendered various kinds of associations in the participants, which influenced the user experience. The participants recalled places that the prototype resembled in their mind, and about which they also described their feelings.

The first colour, light and movement combination showed white twinkling lights. The participants stated that it felt like they had entered a theatre, outer space, an observatory or were under a night sky (Figure 3). The association with a night sky also made the prototype feel spacious and one of the participants wondered whether it might help claustrophobia.

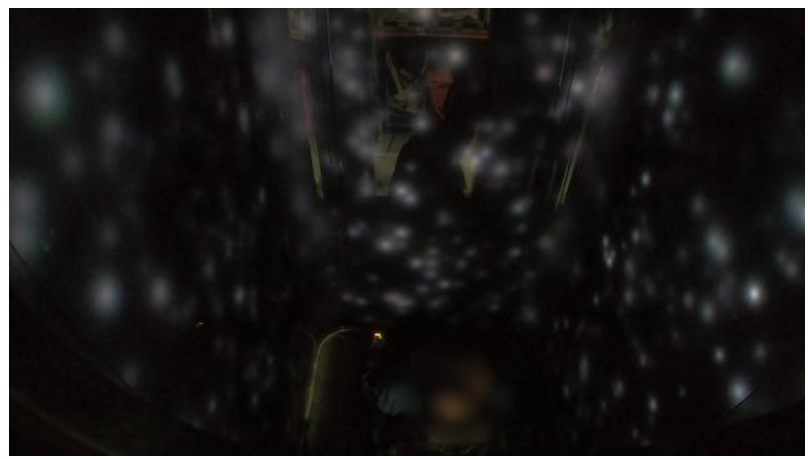

Figure 3. The view associated with, for example, a night sky.

As the colour, light and movement combinations changed (Figure 4), they also changed the associations they created. The blue colour was regarded as having a cold and calming effect, and as if having been underwater or underneath the sky, in an aquarium, an aeroplane or on top of a tall building. The red colour was regarded as warm, energetic and reminded the participants of partying, even being in a disco. The yellow colour was also regarded as warm but was associated with the sun,

2 Jacobson, S. (forthcoming), "Experts by Experience as Contributors to Research and Development in a Corporate Context", UD2021 International conference on Universal Design, Aalto University, Espoo, 9-11 June 2021. [Originally UD2020 but postponed due to COVID-19.]

3 Lönnqvist, R. (2020), Development Directions for Interactive Media Surfaces in an Elevator Context, [MA thesis], Aalto University School of Arts, Design and Architecture. 
summer, being on the beach and felt like looking through sunglasses. For one participant, it felt like being in a bowling alley, even though she could not explain why. The green colour was associated with Christmas and golf. One participant saw a grid under the green colour that made him think of safety glass and a public location. In addition to the colours, the moving lights created associations with the shapes of fish, for example. The prototype as a whole was further associated with a hotel, spa, amusement park, waves, raindrops, a moving rainbow, a light show and also something related to IT with wires.

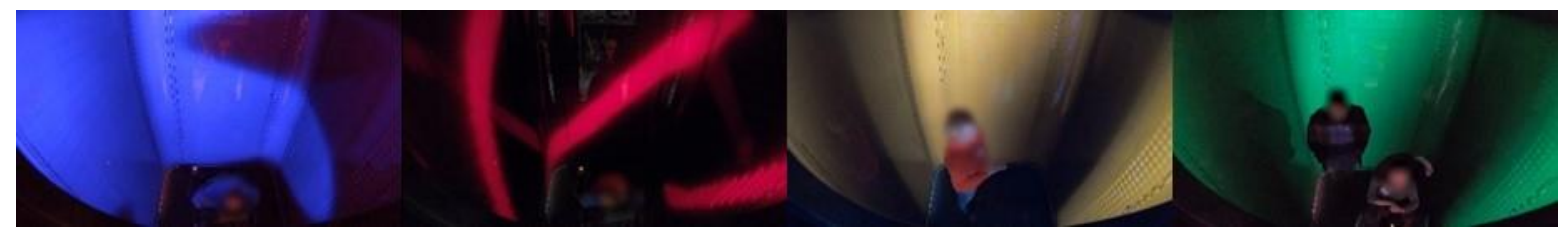

Figure 4. Different colour, light and movement combinations demonstrated by the prototype.

The participants primarily regarded the prototype as being positive, although dark, and they also regarded it as being temperate, yet lively and even "cool". It was only the zigzag movements of colours and lights that they thought might possibly cause dizziness. In fact, the personal assistant of one of the participants had to leave the prototype because he did not feel well. Overall, slower and upward or downward movements were regarded as more pleasant and relaxing than faster and lateral movements. The interactive part of the media surface was exciting, fun and playful and the participants thought it resembled drawing. One of the participants became almost mesmerised by it. With only one seeing eye, she closely followed how the prototype reacted to her hand movements. In addition to associations, the participants considered and, in the design game, also ideated, potential additional uses for the prototype and similar products. Some of their suggestions related to accessibility, for example, the possibility of recognising that a person uses an assistive product and informing them about an accessible route. Some other suggestions extended beyond accessibility. In particular, the interactive media surface was regarded as fun or a form of entertainment, a leisure activity, a means of channelling a person's creativity, expressing feelings, enhancing well-being and also enabling social interaction and creating a sense of belonging.

According to the participants, potential locations for interactive media surfaces, apart from elevators, could include various kinds of waiting areas and lobbies, for example, at airports or in hospitals and shopping centres. Because it was possible to interact with the surface without touching it, the participants considered it to be hygienic and particularly suitable from a healthcare perspective. When asked for feedback about developing the prototype, the participants proposed adding auditory features such as voice control.

\section{DISCUSSION AND CONCLUSIONS}

This exploratory research paper has discussed experiential product qualities and their effects on user experience. The focus has been on products that have accessible and assistive uses but may provide an ambiguous user experience. An elevator has been used as an example. Based on the findings of a preliminary user study, the paper has shown that experiential product qualities can result in a richer user experience in terms of various associations and applications that extend beyond accessibility and the original use.

As they are inherently accessible, elevators are interesting products to examine with regard to the importance and potential of their experience-related qualities. Elevators are assistive by nature and for people with disabilities they may be the only way to move between floors. However, in order to provide a holistic and pleasurable user experience, other qualities are required. Elevators can function as an accessible basis for more experiential qualities that focus on, for example, excitement.

Qualities related to user experience, particularly those qualities that offer multisensory stimuli, also influence accessibility. They enhance usability as they provide consistent information through the different senses. They also enhance experience by offering users qualities that extend beyond accessibility. Experiential qualities can transform accessible products into solutions in which accessibility is not their only, or even their primary, purpose, but without compromising usability. 
Users who have varying abilities are able to detect the assistive product qualities that they need, while other users may not even register these qualities. Multisensory stimuli can be used in this kind of "ondemand accessibility". As described in the previous chapter, users with visual impairments, for example, can detect sound signals in their surroundings that tell them when to proceed and in which direction. For other users, such signals may not be noticed, or they may be designed to provide, for example, an aesthetic experience. Experiential qualities and multisensory stimuli in the environment can be used to create and enhance multiple dimensions of the user experience.

With regard to elevators, experiential qualities can be used to turn the fear of claustrophobia, acrophobia and social situations into something positive by directing the user's attention and providing other cues on which to focus. This user study suggests that adding qualities that enhance experience can lead to a solution that is more positively received. These qualities could help users make familiar associations and also suggest additional applications and locations for a product. This could all result in a richer user experience. This paper has focused on an elevator but also other accessible and assistive products are likely to benefit from adding experiential qualities. There is a myriad of possibilities for enhancing accessibility. However, assistive product qualities need to remain detectable to those users who are dependent on them.

This has been a preliminary user study. The prototype was an early version and was only tested on four participants. However, because the prototype was incomplete, users' feedback could be taken into consideration before the final design decisions were made. Regardless of the intention to include more multisensory qualities, the prototype ended up being dominated by visual qualities. This was due to technical and scheduling issues in a demanding external project with multiple operators and interdependencies. The participating users proposed that auditory and perhaps even olfactory qualities could also be considered. This illustrates the users' contribution and the value of engaging them in the study. Further studies with diverse users will be needed in order to develop more advanced versions of the product.

\section{ILLUSTRATIONS}

Figures 1, 3-4. Drawings made and video snapshots taken by Rasmus Lönnqvist. Figure 2. The photograph is by Saga-Sofia Santala.

\section{ACKNOWLEDGMENTS}

The authors would like to thank the anonymous reviewers for their comments, which have helped improve the paper. The authors further express their gratitude to their colleagues at KONE for their assistance in the user study. The InSCOPE project received funding from the European Union's Horizon 2020 research and innovation programme under grant agreement no. 731671.

\section{REFERENCES}

Coleman, R, Lebbon, C., Clarkson, J. \& Keates, S. (2003), "From margins to mainstream”, In: Clarkson, J., Coleman, R., Keates, S. and Lebbon, C. (Eds.), Inclusive Design: Design for the whole population, 2nd printing, Springer-Verlag, London, pp. 1-25.

Bertelson, P. and De Gelder, B. (2004), "The psychology of multimodal perception”, In: Spence, C. and Driver, J. (Eds.), Crossmodal Space and Crossmodal Attention, Oxford University Press, Oxford, pp. 141-177. https://dx.doi.org/10.1093/acprof:oso/9780198524861.001.0001

Dal Palù, D., De Giorgi, C., Lerma, B. and Buiatti, E. (2018), Frontiers of sound in design: A guide for the development of product identity through sounds, Springer, Cham, Available at: https://link.springer.com/book/10.1007\%2F978-3-319-76870-0 (accessed 18 November 2020). https://dx.doi.org/10.1007/978-3-319-76870-0

Desmet, P. and Hekkert, P. (2007), "Framework of product experience", International Journal of Design, Vol. 1 No. 1, pp. 13-23, Available at: http://www.ijdesign.org/index.php/IJDesign/article/view/66/15 (accessed 17 November 2020).

Egmond, R. V. (2008), “The experience of product sounds”, In: Schifferstein, H. and Hekkert, P. (Eds.), Product experience, Elsevier, pp. 69-89, Available at: https://doi.org/10.1016/B978-008045089-6.50006-X (accessed 17 November 2020). https://dx.doi.org/10.1016/B978-008045089-6.50006-X

InSCOPE (2020), Project, Available at: https://inscope-project.eu/project/ (accessed 2 July 2020).

Jacobson, S. (2009), "Discovering the Accessibility Potential in the Environment", Include 2009 Inclusive design into innovation: transforming practice in design, research and business, Royal College of Art, London, UK, 5-8 April 2009, Available at: https://www.rca.ac.uk/research-innovation/research-centres/helen- 
hamlyn-centre/knowledge_exchange/include-conferences/include-2009/include-2009-proceedings/ (accessed 1 July 2020).

Jacobson, S. (2014), Personalised Assistive Products: Managing Stigma and Expressing the Self, Aalto University publication series doctoral dissertations, 1/2014, Aalto University School of Arts, Design and Architecture, Helsinki, Available at: https://aaltodoc.aalto.fi/handle/123456789/13321 (accessed 2 July 2020).

James, K., Vinci-Booher, S. and Munoz-Rubke, F. (2017), “The impact of multimodal-multisensory learning on human performance and brain activation patterns”, In: Oviatt, S., Schuller, B., Cohen P., Sonntag, D., Potamianos, G., and Krüger A. (Eds.), The Handbook of Multimodal-Multisensor Interfaces, Volume 1: Foundations, User Modeling, and Common Modality Combinations, Association for Computing Machinery and Morgan \& Claypool, New York, pp. 51-94, Available at: https://dl.acm.org/doi/10.1145/3015783.3015787 (accessed 18 November 2020). https://dx.doi.org/10.1145/3015783.3015787

Jokiniemi, J. (2007), Kaupunki kaikille aisteille. Moniaistisuus ja saavutettavuus rakennetussa ympäristössä [City for All Sense - Accessibility and Cross-Modality in the Built Environment], Doctoral dissertation, Teknillisen korkeakoulun arkkitehtiosaston tutkimuksia 2007/29, Teknillinen korkeakoulu, Arkkitehtiosasto, Kaupunkisuunnittelu, Espoo.

KONE (2020a), Company, Available at: https://www.kone.com/en/company/\#item-101800 (accessed 3 March 2021).

KONE (2020b), News and insights, Available at https://www.kone.com/en/news-and-insights/stories/universaldesign.aspx (accessed 14 Oct 2020).

KONE (2020c), Vision and strategy, Available at: https://www.kone.com/en/company/vision-and-strategy/ (accessed 28 Oct 2020).

Mueller, J. (2003), "Universal products in the US", In: Clarkson, J., Coleman, R., Keates, S. and Lebbon, C. (Eds.), Inclusive Design: Design for the whole population, 2nd printing, Springer-Verlag, London, pp. 318-335.

Oviatt, S. (2017), “Theoretical Foundations of Multimodal Interfaces and Systems”, In: Oviatt, S., Schuller, B., Cohen P., Sonntag, D., Potamianos, G., and Krüger A. (Eds.), The Handbook of Multimodal-Multisensor Interfaces, Volume 1: Foundations, User Modeling, and Common Modality Combinations, Association for Computing Machinery and Morgan \& Claypool, New York, pp. 19-50, Available at: https://doi.org/10.1145/3015783.3015786 (accessed 13 November 2020). https://dx.doi.org/10.1145/3015783.3015786

Roto, V, Law, E., Vermeeren A. and Hoonhout, J. (Eds.) (2011), User experience white paper: Bringing clarity to the concept of user experience, Result from Dagstuhl Seminar on Demarcating User Experience, September 15-18, 2010, Available at: http://www.allaboutux.org/files/UX-WhitePaper.pdf (accessed 13 November 2020).

Rousi, R. (2013), "The experience of no experience Elevator UX and the role of unconscious experience", Proceedings of International Conference on Making Sense of Converging Media, pp. 289-292, Available at: https://dl.acm.org/doi/10.1145/2523429.2523455 (accessed 30 Oct 2020). https://dx.doi.org/10.1145/2523429.2523455

Rousi, R. (2014), “Unremarkable experiences - Designing the user experience of elevators", Swedish Design Research Journal, Vol. 11 No. 1, pp. 47-52, Available at: https://svid.ep.liu.se/article/view/522/104 (accessed 30 Oct 2020). https://dx.doi.org/10.3384/svid.2000-964X.14147

Schifferstein, H. and Spence, C. (2008), "Multisensory product experience", In: Schifferstein H., and Hekkert, P. (Eds.), Product experience, Elsevier Science, pp. 133-161, Available at: https://www.sciencedirect.com/science/article/pii/B9780080450896500083?via\%3Dihub (accessed 16 October 2020). https://dx.doi.org/10.1016/B978-008045089-6.50008-3

Sonneveld, M. and Schifferstein, H. (2008), "The tactual experience of objects", In: Schifferstein H., and Hekkert, P. (Eds.), Product experience, Elsevier Science, pp. 41-67, Available at: https://www.sciencedirect.com/science/article/pii/B9780080450896500058?via\%3Dihub (accessed 16 October 2020). https://dx.doi.org/10.1016/B978-008045089-6.50005-8

The Center for Universal Design (1997), The Principles of Universal Design, NC State University, Available at: https://projects.ncsu.edu/ncsu/design/cud/about_ud/udprinciplestext.htm (accessed 1 July 2020). 